\title{
ANALISIS PENGGUNAAN HURUF KAPITAL DAN TANDA BACA PADA PARAGRAF DESKRIPTIF SISWA KELAS 4 SDN BINONG II KABUPATEN TANGERANG
}

\author{
Ana Mariana Purnamasari ${ }^{1}$, Ina Magdalena ${ }^{2}$, Asih Rosnaningsih ${ }^{3}$ \\ Universitas Muhammadiyah Tangerang, Indonesia \\ e-mail: anamarianap@yahoo.co.id, inapgsd@gmail.com, asihrosna@gmail.com,
}

\begin{abstract}
Abstrak
Penelitian ini bertujuan untuk mengetahui kesalahan siswa dalam menggunakan huruf kapital dan tanda baca pada paragraf deskriptif pada siswa kelas 4 SDN Binong II Kabupaten Tangerang. Me tode y ang digunakan dalam penelitian ini a dalah metode kualitatif deskriptif, yaitu mengkajidan menganalisis d a ta secara objektif sesuai dengan data yang ditemukan di la pangan. Kemudian data yang terkumpul dari hasil penelitian dideskripsikan dalam bentuk kata-kata. Hasil penelitian iniditemukan 49 tulisan sis wa yang telah dianalisis. Terhadap penulisan huruf kapital siswa pada paragraf deskriptif, sebanyak 403 kesa lahan sedangkan perletakkan tanda baca pada paragraf deskriptif yang telah ditulis siswa sebanyak 72 kesalahan.
\end{abstract}

Kata kunci: Huruf kapital, ta nda baca, paragraf deskriptif.

\begin{abstract}
This study aims to determine students' mistakes in using capital letters and punct uation in descriptive paragraphs in grade 4 students of SDN Binong II, Tangerang Regency. The method used in this research is descriptive qualitative method, which is to study and analyze data objectively in accordance with the data found in the field. Then the data collected from the research results are de scribed in the form of words. The results of this study found 49 students writings that have been analyzed. For writ ing capital letters of students in descriptive paragraphs, as many as 403 errors while placing punctuation in descriptive paragraphs that students have written as many as 72 errors.
\end{abstract}

Keywords: Capital letters, punctuation, descriptive paragraphs.

\section{PENDAHULUAN}

Pendidikan merupakan suatu hal yang sangat penting dan tidak bisa lepas dari kehidupan, karena pendidikan merupakan suatu kebutuhan. Kualitas bangsa yang maju, tidak lepas dari kualitas pendidikan Sumber Daya Manusia yang baik, dan berbudi pekerti yang baik. Sistem pendidikan di Indonesia menerapkan wajib belajar 9 tahun pada penduduk, jenjang pendidikan yang wajib ditempuh 9 tahun adalah jenjang pendidikan dasar yang terdiri dari 6 tahun Sekolah Dasar, dan 3 tahun Sekolah Menengah Pertama, pernyataan ini seiring dengan Undang- Undang Republik Indonesia No. 20 Tahun 2003 tentang Sistem Pendidikan Nasional BAB IV Hak dan Kewajiban Warga Negara, Orang Tua, Masyarakat dan Pemerintah Pasal 6 (Ayat 1) yang berbunyi, "Setiap warga negara yang berusia tujuh tahun sampai dengan 15 tahun wajib mengikuti pendidikan dasar". 


\section{Indonesian Journal of Elementary Education \\ Vol.1 No.1 Desember 2019 \\ E-ISSN 2722-6689 \\ http://jurnal.umt.ac.id/index.php/lJOEE}

Bahasa Indonesia digunakan manusia untuk berkomunikasi di dalam kehidupan sehari-hari. Keberadaan bahasa sangat penting bagi manusia. Tanpa adanya bahasa, interaksi dan segala macam kegiatan dalam masyarakat akan lumpuh. Bangsa Indonesia dipersatukan oleh Bahasa Indonesia yang sangat berguna untuk terjalinnya suatu komunikasi yang baik. Tujuan mata pelajaran Bahasa Indonesia, yakni untuk mengembangkan kemampuan siswa berkomunikasi baik lisan maupun tulisan, membuat siswa menjadi lebih terampil dalam berbahasa Indonesia, siswa mampu berekspresi dan menikmati sastra, sebagai alat untuk mempelajari rumpun pelajaran lain, berpikir kritis dalam berbagai aspek kehidupan, serta mengembangkan sikap menghargai Bahasa Indonesia sebagai bahasa nasional

Berdasarkan penelitian awal di SDN Binong II pada hari Sabtu, 27 Oktober 2018 dengan mewawancarai guru kelas, di kelas 4 tentang mata pelajaran Bahasa Indonesia mengenai Penggunaan huruf kapital dan tanda baca pada siswa kelas 4 SDN Binong II Kabupaten Tangerang, dapat diketahui bahwa siswa-siswi mengalami kesulitan dalam menggunakan huruf kapital dan tanda baca pada paragraf deskriptif. Penguasaan bahasa tulis mutlak diperlukan dalam kehidupan modern sekarang ini, ternyata keterampilan menulis kurang mendapat perhatian.

Sebagai suatu keterampilan berbahasa, menulis adalah suatu kegiatan penyampaian pesan (komunikasi) dalam menggunakan bahasa tulis sebagai alat medianya. Pesan adalah isi atau muatan yang terkandung dalam suatu tulisan. Tulisan merupakan sebuah simbol atau lambang bahasa yang dapat dilihat dan disepakati pemakaiannya. Menulis adalah, salah satu cara untuk manusia bisa berkomunikasi dengan manusia yang lain nya. Menurut Ishak (2014), "Menulis adalah upaya melakukan komunikasi dengan pembaca" (h.5). Hal disini bukan komunikasi timbal balik tetapi, komunikasi sepihak, namun memerlukan strategi dan argumentasi sebagai suatu cara yang sangat berguna. Sedangkan menurut Saleh (2013), "Menulis adalah rangkaian kegiatan seseorang yang meliputi pengungkapan ide-ide, gagasan, buah pikiran, pendapat yang baru, yang bersumber dari pengalaman nyata penulisnya, dengan menggunakan kata-kata yang baik, disusun secara kronologis dengan menggunakan kalimat yang jelas, dan paragraf yang baik serta ditulis dengan menggunakan EYD yang benar, sehingga dapat dipahami oleh orang lain/pembaca" (h.31). Berdasarkan teoriteori diatas, dapat disimpulkan bahwa menulis adalah kegiatan komunikasi tidak 


\section{Indonesian Journal of Elementary Education \\ Vol.1 No.1 Desember 2019 \\ E-ISSN 2722-6689 \\ http://jurnal.umt.ac.id/index.php/lJOEE}

langsung, dan yang membaca tulisan tersebut disebut sebagai pembaca, menulis merupakan wadah untuk mengekspresikan melalui tulisan yang di rangkai dengan baik dan suatu keterampilan yang perlu dilatih.

Menulis harus menggunakan aturan-aturan yang terdapat dalam bahasa Indonesia. Sebagai pemakai bahasa, kita wajib mematuhi aturan baku berbahasa yang dinyatakan dalam Pedoman Umum Ejaan Bahasa Indonesia atau yang lebih dikenal dengan PUEBI. Adalah yang dimaksud dengan ejaan adalah keseluruhan peraturan bagaimana melambangkan bunyi ujaran dan bagaimana antar hubungan antara lambang lambang itu (pemisahan dan penggabungannya dalam suatu bahasa). Secara teknis yang dimaksud dengan ejaan adalah penulisan huruf, penulisan kata, dan pemakaian tanda baca. Bentuk tulisan yang baik adalah tulisan yang memperhatikan penggunaan huruf, penggunaan tanda baca dan lain-lain.

Di dalam menulis paragraf penulisan huruf kapital dan tanda baca perlu ditingkatkan dan dimengerti oleh setiap pemakai Bahasa Indonesia, khususnya bagi siswa-siswi. Tidak hanya huruf kapital saja, penggunaan dan peletakkan tanda baca juga perlu dipahami untuk menunjang peningkatan keterampilan dalam berbahasa. Penerapan penulisan huruf kapital merupakan aturan-aturan yang harus ditaati oleh pemakai bahasa untuk keteraturan dan keseragaman bentuk dalam bahasa tulis. Di dalam penulisan Huruf kapital adalah huruf abjad yang ukurannya lebih besar di bandingkan huruf lainnya, yang biasa nya digunakan untuk awal kalimat, nama orang, keterangan nama tempat, dan sebagainya. Menurut Turniawan(2018), "Huruf kapital adalah huruf yang berukuran dan berbentuk lebih besar dari huruf biasa" (h. 3). Jadi, huruf kapital adalah huruf yang memiliki ukuran dan bentuk huruf nya yang lebih besar di bandingkan huruf-huruf lainnya.

Pemaparan lainnya juga dibenarkan Arifin dan Tasai (2009) menyatakan bahwa, "Huruf Besar atau Huruf Kapital, penulisan huruf kapital yang kita jumpai dalam tulisan-tulisan resmi kadang-kadang menyimpang dari kaidah-kaidah yang berlaku" (h.175). Maksud di sini, huruf kapital juga disebut huruf besar, dan biasanya terjadi kesalahan dalam penulisan nya yang menyimpang dari aturan-aturan yang berlaku. Adapun Sugiarto (2013) menyatakan bahwa, "Huruf kapital sering di ganti dengan istilah huruf besar. Namun istilah ini agak membingungkan karena pada kenyataanny a 
ada huruf kecil yang besar (ukurannya) dan ada huruf besar yang kecil (ukurannya)" (h. 11). Itu artinya, huruf kapital tidak bisa disebut juga huruf besar, karena tidak semua huruf yang ukurannya besar disebut huruf kapital begitu pun sebaliknya.

Sedangkan Tanda Baca adalah suatu simbol yang memiliki arti tertentu yang digunakan di dalam komunikasi tidak langsung, yaitu tulisan dan menurut Chaer (2011) tanda baca adalah, "Tanda-tanda yang digunakan di dalam bahasa tulis agar kalimatkalimat yang kita tulis dapat dipahami orang persis seperti yang kita maksudkan" (h.72). Jadi, di dalam bahasa tulis, tanda baca sangat berguna untuk membantu pemahaman bagi pembaca nya agar sesuai dengan maksud pesan yang ingin disampaikan penulis kepada pembacanya, dalam perannya dikatakan oleh Sugiarto (2013) Peran Tanda baca, "Peran tanda baca adalah sangat penting. Keberadaan tanda baca dalam sebuah tulisan akan sangat membantu pembaca memahami sebuah tulisan"(h.46). Jadi, ketika suatu bentuk tulisan tidak diberi keterangan tanda baca, akan mempersulit pembaca memahami makna dari suatu tulisan, begitupun sebaliknya. Berikut jenis-jenis Tanda Baca yang lazim digunakan menurut (Chaer, 2011, h. 72).

Berdasarkan pengalaman dan pengamatan di kelas saat observasi ke SDN Binong II masih banyak terjadi kesalahan dalam penulisan huruf kapital dan tanda baca. Ini berarti kemampuan siswa dalam memahami huruf kapital dan tanda baca tergolong masih rendah. Kesalahan penulisan huruf kapital dan tanda baca yang kurang tepat sering terjadi dalam tulisan siswa. Hal ini disebabkan ketidaktahuan siswa dalam penulisan huruf kapital dan tanda baca, metode pembelajaran yang digunakan guru kurang efektif khususnya untuk materi huruf kapital dan tanda baca sehingga mengakibatkan siswa belum mampu memahami penulisan huruf kapital dan tanda baca secara tepat dan benar, guru kurang menekankan siswa untuk membiasakan menulis dengan memperhatikan penulisan huruf kapital dan tanda baca. Berdasarkan masalah yang telah dipaparkan, peneliti tertarik untuk melakukan penelitian dengan judul "Analisis Penggunaan Huruf Kapital dan Tanda Baca pada Paragraf Deskriptif Siswa Kelas 4 SDN Binong II“.

\section{METODE PENELITIAN}

Metode yang digunakan di dalam penelitian ini adalah metode kualitatif.Penelitian Kualitatif bersifat Deskriptif adalah penelitian yang bertujuan 
menjelaskan sesuatu seperti apa adanya (as it is) secara mendalam. Langkah kerja untuk mendeskripsikan suatu objek, fenomena, atau latar sosial sasaran penelitian terejawantah dalam tulisan naratif. Artinya, data maupun fakta yang telah dihimpun oleh peneliti kualitatif berbentuk kata atau gambar. Mendeskripsikan sesuatu berarti menggambarkan apa, mengapa, dan bagaimana suatu kejadian terjadi.Populasi dalam penelitian ini adalah siswa kelas IV di SDN Binong II Kabupaten Tangerang, yang berjumlah 49 siswa.Untuk memperoleh data-data yang diperlukan dalam penelitian ini, peneliti menggunakan Triangulasi Teknik yaitu, observasi, wawancara dan dokumentasi.

\section{HASIL PENELITIAN}

Temuan ketidaksesuaian penulisan huruf kapital dan tanda baca menurut PUEBI.

Berikut ini ditemukan sebanyak 49 responden siswa di SDN Binong II Kabupaten Tangerang,dengan salah satu contoh dari responden siswa 1 sebagai berikut:

Tabel 1. Hasil Responden 1

\begin{tabular}{|c|c|c|}
\hline $\begin{array}{l}\text { Responden } \\
\text { Siswa }\end{array}$ & $\begin{array}{c}\text { Kesalahan Karangan } \\
\text { Siswa }\end{array}$ & $\begin{array}{c}\text { Rekomendasi Perbaikan } \\
\text { Karangan Siswa }\end{array}$ \\
\hline 1 & 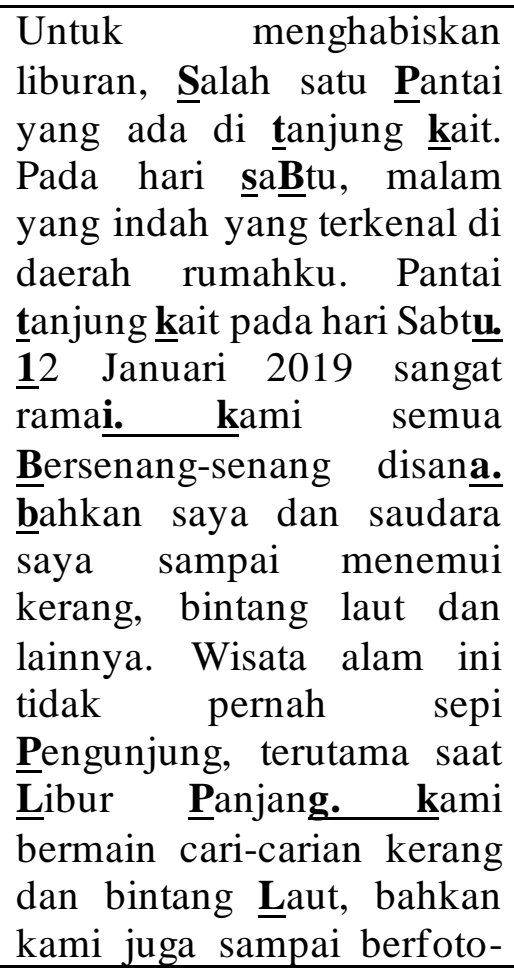 & $\begin{array}{l}\text { Untuk menghabiskan liburan, } \\
\text { salah satu pantai yang ada di } \\
\text { Tanjung } \underline{\text { K}} \text { ait. Pada hari } \underline{\text { Sabtu}} \text {, } \\
\text { malam yang indah yang } \\
\text { terkenal di daerah rumahku. } \\
\text { Pantai Tanjung Kait pada hari } \\
\text { Sabtu, } 2 \text { Januari } 2019 \text { sangat } \\
\text { ramai. Kami semuabersenang- } \\
\text { senang disana, bahkan saya } \\
\text { dan saudara saya sampai } \\
\text { menemui kerang, bintang laut } \\
\text { dan lainnya. Wisata alam ini } \\
\text { tidak pernah sepi pengunjung, } \\
\text { terutama saat libur panjang. } \\
\text { Kami bermain cari-carian } \\
\text { kerang dan bintang laut, } \\
\text { bahkan kami juga sampai } \\
\text { berfoto-foto. }\end{array}$ \\
\hline
\end{tabular}


http://jurnal.umt.ac.id/index.php/lJOEE

\begin{tabular}{|l|l|l|}
\hline $\begin{array}{c}\text { Responden } \\
\text { Siswa }\end{array}$ & \multicolumn{1}{|c|}{$\begin{array}{c}\text { Kesalahan Karangan } \\
\text { Siswa }\end{array}$} & $\begin{array}{c}\text { Rekomendasi Perbaikan } \\
\text { Karangan Siswa }\end{array}$ \\
\hline & foto. & \\
& & \\
& & \\
& & \\
& & \\
& & \\
& & \\
& & \\
& & \\
\end{tabular}

Pada tabel di atas dengan responden siswa 1, terdapat kesalahan penulisan siswa dalam penulisan karangannya yaitu, kesalahan penulisan huruf kapital atau pun kesalahan penggunaan tanda baca di dalamnya. Dan terdapat rekomendasi perbaikan menurut PUEBI di kolom sebelahnya.

Tabel 2. Analisis Penggunaan Responden Siswa 1

\begin{tabular}{|c|c|c|c|c|c|c|c|c|}
\hline \multirow{4}{*}{$\begin{array}{c}\text { Responden } \\
\text { Siswa }\end{array}$} & \multicolumn{6}{|c|}{ Hualisis Penggunaan } \\
\cline { 2 - 8 } & $\begin{array}{c}\text { AK, } \\
\text { TK }\end{array}$ & STB & $\begin{array}{c}\text { NH } \\
\text { NB }\end{array}$ & NO & NT & Titik & Koma & $\begin{array}{c}\text { Titik } \\
\text { dua }\end{array}$ \\
\hline 1 & 7 & 2 & 2 & - & 4 & 2 & - & - \\
\hline
\end{tabular}

Berdasarkan tabel di atas pada responden siswa 1, terdapat 7 kesalahan di aw al kalimat dan tengah kalimat, 2 kesalahan setelah tanda baca, 2 kesalahan di nama hari dan nama bulan, 4 kesalahan di nama tempat, dan 2 kesalahan tanda baca titik.

Tabel 3. Tabel Rekapitulasi

\begin{tabular}{|c|c|c|}
\hline No. & Hasil Analisa & Jumlah Temuan \\
\hline
\end{tabular}


http://jurnal.umt.ac.id/index.php/lJOEE

\begin{tabular}{|c|c|c|}
\hline No. & Hasil Analisa & Jumlah Temuan \\
\hline 1. & $\begin{array}{c}\text { Huruf Kapital } \\
\text { a. Awal Kalimat, Tengah Kalimat }\end{array}$ & 175 \\
\hline & b. Setelah Tanda Baca & 52 \\
\hline & c. Nama Hari dan Nama Bulan & 50 \\
\hline & d. Nama Orang & 13 \\
\hline & e. Nama Tempat & $\mathbf{4 0 3}$ \\
\hline Total: & $\begin{array}{r}\text { Tanda Baca: } \\
\text { a. Titik }\end{array}$ & 48 \\
\hline 2. & b. Koma & 23 \\
\hline & c. Titik Dua & 13 \\
\hline
\end{tabular}

Berdasarkan tabel 4.109 tersebut dapat dilihat bahwa hasil analisis huruf kapital dan tanda baca di lembar hasil tes tulisan siswa dalam paragraf deskriptif. Analisis data ini disajikan dengan membuat table frekuensi yang dilengkapi dengan persentase. Untuk huruf kapital yang berada di awal kalimat, tengah kalimat terdapat $44 \%$, setela h tanda baca terdapat $13 \%$, nama hari dan nama bulan terdapat $12 \%$, nama orang terdap at 3 $\%$, nama tempat terdapat $28 \%$. Dan kesalahan tada baca titik terdapat $67 \%$, koma terdapat $32 \%$, dan titik dua terdapat $1 \%$ di SDN Binong II Kabupaten Tangerang.

Pengumpulan data berlangsung selama 1 hari yaitu, pada hari Sabtu, 11 Mei 2019. Pada hari Sabtu tersebut, peneliti menyerahkan surat izin penelitian ke sekolah untuk diizinkan melakukan penelitian serta menjelaskan maksud dan tujuan melakukan penelitian. Kemudian peneliti melakukan wawancara kepada beberapa siswa dan peneliti memberi sedikit teori untuk mengingat kembali tentang membuat paragraf deskripsi dan penggunaan huruf kapital serta tanda baca. Setelah itu siswa menulis karangan deskripsi di kelas. Wawancara ini juga digunakan untuk mengetahui hal-hal yang berhubungan dengan pengetahuan siswa dalam membuat paragraf deskriptif, khususnya dalam penggunaan huruf kapital dan tanda baca yang baik dan ben ar. Pada hari Sabtu peneliti mengumpulkan data yang berupa dokumentasi, hasil tulisan siswa dalam bentuk karangan sederhana, dengan jumlah keseluruhan siswa sebanyak 49 siswa. Kemampuan menulis dengan menerapkan kaidah penulisan huruf kapital dan 


\section{Indonesian Journal of Elementary Education \\ Vol.1 No.1 Desember 2019 \\ E-ISSN 2722-6689 \\ http://jurnal.umt.ac.id/index.php/lJOEE}

tanda baca secara tepat dari hasil tulisan siswa dalam membuat karangan sederhana ternyata sangat bervarasi. Penelitian yang dilakukan pada hari Sabtu, 11 Mei 2019 menyampaikan kepada kepala sekolah bahwa penelitian telah selesai dilaksanakan namun jika ada data-data yang masih kurang maka peneliti diperbolehkan untuk datang lagi ke sekolah. Peneliti hanya akan meneliti tentang tanda baca berupa tanda titik, koma dan titik dua sebagaimana seperti yang sudah dijelaskan di BAB II. Berikut ini peneliti akan menguraikan tentang kesalahan siswa dalam penulisan huruf kapital dan tanda baca pada paragraf deskriptif.

Berdasarkan hasil wawancara dan analisis tulisan siswa, peneliti menyimpulkan bahwa siswa memang mengalami kesulitan dalam menggunakan huruf kapital dan tanda baca yang sesuai dengan PUEBI, berikut penjabaran secara detailny a responden siswa 1:

1. Penulisan huruf kapital yang tepat sesuai PUEBI : "Huruf kapital dipakai sebagai huruf pertama awal kalimat", "Huruf kapital dipakai sebagai huruf pertama nama geografi”.

Kalimat di atas kurang tepat, seharusnya huruf “s, p, b, \& 1" pada kata "Salah satu”, "Pantai", "Bersenang-senang", "Pengunjung", "Libur", "Panjang" dan "Laut" menggunakan huruf kecil karena tidak terdapat pada awal kalimat, yaitu di dalam PUEBI disebutkan "Huruf kapital dipakai sebagai huruf pertama awal kalimat". Dan huruf " $t \&$ k" pada kata "tanjung kait" seharusnya menggunakan huruf kapital karena, di dalam PUEBI disebutkan "Huruf kapital dipakai sebagai huruf pertama nama geografi”.

2. Penulisan tanda baca yang tepat sesuai PUEBI : "Tanda koma dipakai diantara nama dan alamat bagian-bagian alamat, tempat dan tanggal, serta nama tempat dan wilayah atau negeri yang di tulis berurutan".

Dan seharusnya diberikan tanda baca “," setelah kata "Sabtu” karena, merupakan keterangan nama hari dan sebelum keterangan tanggal. Dan seharusnya diberikan tanda baca "," setelah kata "disana" karena, berada di pertengahan kalimat yaitu, di dalam PUEBI disebutkan "Tanda koma dipakai diantara nama dan alamat bagianbagian alamat, tempat dan tanggal, serta nama tempat dan wilayah atau negeri yang di tulis berurutan". 


\section{KESIMPULAN DAN SARAN}

Berdasarkan kajian teoritis dan hasil penelitian yang telah dilakukan mengenai “ Analisis Penggunaan Huruf Kapital dan Tanda Baca pada Paragraf Deskriptif siswa kelas 4 SDN Binong II Kabupaten Tangerang ". Maka peneliti dapat menyimpulkan bahwa kesalahan penulisan huruf kapital siswa masih banyak di temukan dengan jumlah total 403 kesalahan yang terdiri dari kesalahan di awal kalimat dan tengah kalimat $44 \%$, setelah tanda baca $13 \%$, nama hari dan nama bulan $12 \%$, nama orang $3 \%$ dan nama tempat $28 \%$. Jenis kesalahan yang banyak dilakukan siswa yaitu, pada bagian awal kalimat atau pun di tengah kalimat, setelah tanda baca, nama hari dan nama bulan, nama orang dan nama tempat. Penulisan tanda baca titik, koma, dan titik dua memiliki aturan penggunaan di dalam PUEBI, guna menghindari kebermaknaan arti dari sebuah kalimat. Jenis kesalahan tanda baca pada tulisan siswa di temukan dengan total kesalahan 72 kesalahan. Yaitu dengan rincian kesalahan tanda baca titik $67 \%$, koma $32 \%$, dan titik dua sebanyak $1 \%$.

Berdasarkan kesimpulan yang telah di jelaskan di atas, ada beberapa saran yang diajukan oleh penulis. Pertama, guru harus lebih meningkatkan lagi kreatifitas cara menulis huruf kapital menurut PUEBI yang baik dan benar sesuai dengan penggunaannya. Kedua, Peneliti harus lebih rajin lagi dalam membaca buku-buku pembaharuan jika terdapat perubahan peraturan di dalam penggunaan huruf kapital dan tanda baca yang baik dan benar. Agar peneliti tidak tertinggal informasi terbaru tentang materi penggunaan huruf kapital dan tanda baca dan bisa mengajarkan ilmu nya kepada peserta didik nantinya. Ketiga, sekolah harus terus mengadakan kegiatan untuk membina kemampuan guru-gurunya, khususnya untuk meningkatkan mutu pembelajaran penggunaan huruf kapital dan tanda baca dalam pembelajaran Bahasa Indonesia.

\section{DAFTAR PUSTAKA}

Akhadiah, S., Arsjad, M.G., \& Ridwan, S.H. (2012). Pembinaan Kemampuan Menulis Bahasa Indonesia. Jakarta: Erlangga. 


\section{Indonesian Journal of Elementary Education \\ Vol.1 No.1 Desember 2019 \\ E-ISSN 2722-6689 \\ http://jurnal.umt.ac.id/index.php/lJOEE}

Arifin, E. Z, Tasai, S. A. (2 009). Cermat Berbahasa Indonesia untuk Perguruan Tinggi. Jakarta: Akademika Pressindo.

Azwar, S. (2015). Metode Penelitian. Yogyakarta: Pustaka Pelajar.

Bungin, B. (2015). Metodologi Penelitian Kualitatif Aktualisasi Metodologis ke Arah Raga Varian Kontemporer. Jakarta: PT Rajagrafindo Persada.

Chaer, A. (2011). Tata Bahasa Praktis Bahasa Indonesia. Jakarta: PT Rineka Cipta.

Dalman, H. (2016). Keterampilan Menulis. Jakarta: PT RajaGrafindo Persada.

Duwi Rahmadi (2017). Smart Book Pedoman Umum Ejaan Bahasa Indonesia. Solo: Genta Smart Publisher.

Ghony, M.D., Almanshur, F. (2012). Metode Penelitian Kualitatif. Jogjakarta: Ar Ruzz Media.

Ishak, S. (2014). Cara Menulis Mudah. Jakarta:PT Elex Media Komputindo.

Jauhari, H. (2013). Terampil Mengarang Dari Persiapan hingga Presentasi, dari Karangan Ilmiah hingga Sastra. Bandung: Nuansa Cendekia.

Kukuh, F.T., Edy, S., \& Sri, H. (2016). Peningkatan Kemampuan Menulis Paragraf Deskripsi dengan Model Example Non Example pada Siswa Sekolah Menen gah Kejuruan. Jurnal Penelitian Bahasa, Sastra Indonesia dan Pengajarannya Volume 4 Nomor 2.

Kuntarto, N.M. (2008). Cermat dalam Berbahasa Teliti dalam Berpikir. Jakarta: Mitra Wacana Media.

Moleong, L.J. (2012). Metodologi Penelitian Kualitatif. Bandung: PT Remaja Rosdakarya.

Riyadi, Edi. (2015). Metode Statistika Parametrik \& Nonparametrik. Tangerang: Pustaka Mandiri.

Romi. (2014). Analisis Kesalahan Penggunaan Huruf Kapital dan Tanda Baca Dalam Cerpen Siswa Kelas X Sekolah Menengah Atas Negeri 1 Palmatak Tahun Pelajaran 2012/2013.e-journal,4.

Rubi, Y. (2013). Analisis Kesalahan Penggunaan Huruf Kapital dan Tanda Baca pada Karangan Narasi Siswa Kelas VIII Madrasah Tsanawiyah Masani Bintan, EJournal, 2.

Saleh, Z.H.M. (2013). Terampil Menulis di Sekolah Dasar Model Pengembangan Pembelajaran Menulis di Sekolah Dasar. Tangerang: Pustaka Mandiri. 


\section{Indonesian Journal of Elementary Education \\ Vol.1 No.1 Desember 2019 \\ E-ISSN 2722-6689 \\ http://jurnal.umt.ac.id/index.php/lJOEE}

Setyawati, N. (2010). Analisis Kesalahan Berbahasa Indonesia Teori dan Praktik. Surakarta: Yuma Pustaka.

Sugiarto, E. (2013). EYD untuk Pelajar dan Mahasiswa. Yogyakarta: Suaka Media.

Sugiyono. (2015). Metode Penelitian Pendidikan (Pendekatan Kuantitatif, Kualitatif, dan $R \& D)$. Bandung: Alfabeta.

Susanto, A. (2013). Teori Belajar dan Pembelajaran di Sekolah Dasar. Jakarta: Prenadamedia Group.

Turniawan, U. H. (2018). Buku Panduan EBI (Ejaan Bahasa Indonesia). Bandung: UD. Lingkar Media.

Zainurrahman. (2011). Menulis dari Teori hingga Praktik (Penawar Racun Plugiarisme). Bandung: Alfabeta. 